\title{
Incidence and classification of childhood vasculitides in Denmark 1976-I 998 according to the consensus criteria for the classification of childhood vasculitides
}

\author{
RAR Raja*, LLS Soerensen, TH Herlin and SMN Nielsen
}

Address: Pediatric clinic, JMC, Rigshospitalet, Copenhagen and Department of Pediatrics, Aarhus University Hospital Skejby, Aarhus, Copenhagen and Aarhus, Denmark

* Corresponding author

\author{
from 15th Paediatric Rheumatology European Society (PreS) Congress \\ London, UK. 14-17 September 2008 \\ Published: 15 September 2008 \\ Pediatric Rheumatology 2008, 6(SuppI I):P260 doi:10.1 I86/I546-0096-6-SI-P260
}

This abstract is available from: http://www.ped-rheum.com/content/6/SI/P260

C 2008 Raja et al; licensee BioMed Central Ltd.

\section{Background}

In 2006 Ozen et al proposed new diagnostic criteria for the classification of childhood vasculitides. The aim of this retrospective study was to describe the incidence of Wegener's Granulomatosis (WG), Polyarteritis Nodosa (PAN) and Takayasu Arteritis (TA) in Denmark during the period of 1976-1998. Furthermore, we wanted to classify them according to the Chapel Hill Classification Criteria as well as to the new consensus criteria and to compare if this altered the incidence of the different vasculitides.

\section{Methods}

In the Danish National Patient Register (DNPR) we searched for the following diagnosis in children aged 0 16 years:

- Wegener's Granulomatosis

- Polyarteritis Nodosa

- Takayasu Arteritis

- Unclassified primary systemic vasculitides

After compiling the results from this search we contacted the pediatric centres where the patients had originally been admitted, in order to retrieve the relevant charts.

\section{Results}

The total number of patients found in the DNPR with possible vasculitides was 79. 48 patients from 11 Danish pediatric departments were included. 35 of these could not be classified as primary vasculitides. 13 patients were classified as follows: WG 11 and PAN 2. None of the patients changed diagnosis due to re-classification.

\section{Conclusion}

In this retrospective investigation and for these 3 diseases the diagnosis was equal for all patients with respect to the two sets of classification criteria.

A prospective study of classification for all types of childhood vasculitides is ongoing in the regime of PRINTO. 